\title{
LA SEMIÓTICA EN PUERTO RICO
}

\author{
Eliseo R. Colón \\ Escuela de Comunicación Pública \\ Universidad de Puerto Rico
}

Podemos argumentar que las diversas orientaciones del ámbito semiótico se han perfilado en Puerto Rico a través de una pluralidad de intereses e investigaciones. En gran medida, estas investigaciones comprenden una gama de temas que van desde la reflexión filosófica y el análisis textual, hasta la reflexión sociosemiótica. En todos estos trabajos la categoría «discurso» ocupa un lugar preferencial. Desde hace varios años, la noción de sentido discursivo, es decir, la relación entre discurso y producción de sentido, es el eje central de gran parte de la producción investigadora llevada a cabo por los intelectuales puertorriqueños.

Entre esta pluralidad de intereses e investigaciones, uno de los campos más fértiles y más privilegiados por los investigadores ha sido el del análisis textual. Estos trabajos respondieron al desarrollo vertiginoso a partir de los años 60 de las diferentes vertientes del estructuralismo semiótico y las ciencias del lenguaje. Tal vez, algunos de estos 
esfuerzos nos parezcan hoy día simples ejercios metodológicos que nos han mantenido en la encerrona de una hemenéutica estéril.

A grandes rasgos, podríamos decir que la mayoría de los trabajos de la investigación semiótica en estos momentos recorren tres grandes temas: 1) las estructuras textuales y el trazado de los recorridos narrativos; 2) la problemática texto/discurso y sus matrices culturales; 3) la interdiscursividad de redes semioticas que estudia los usos sociales, consumo y modos de «ver»/《leer» de la producción textual.

Con respecto al estudio de las estructuras textuales, estas investigaciones establecen la relación entre texto y discurso. Por ejemplo, se observan las estructuras textuales y los sistemas discursivos, no sólo a partir del análisis estructural, sino que se toma en consideración la gama de redes intertextuales que atraviesan los textos; en otras palabras, el análisis se lleva a cabo a partir del estudio de la materia significante. Otro aspecto de este eje, es la manera en que se organizan los discursos.

El segundo eje en el que se coloca la investigación semiótica es aquél que traza el mapa sociocultural. Estos trabajos elaboran una constitución histórico-antropológica del signo, a la vez que estudian la circulación cultural de las diversas formaciones discursivas. Una pregunta clave de estos estudios es ¿cuál ha sido el papel de los discursos en la formación de una cultura nacional?

En el tercer eje, muy atado al segundo, textos/discursos y sus matrices culturales, se reconoce que toda comunicación es un proceso de negociación y de transacciones, que no puede existir aislada y que constituye una serie de prácticas y saberes comunicativos. Los trabajos de este tercer eje incorporan el concepto de género textual como unidad de análisis. Es así que el énfasis reciente en investigar, entre otros, los procesos de la recepción textual y la producción simbólica han llevado a replantear la necesidad de reorientar las investigaciones del análisis discursivo. Por ejemplo, la incorporación de los postulados sobre la semiótica de antropólogos como Clifford Gertz sirve para problematizar la manera en que estudiamos la diversidad de procesos culturales, tal como los procesos de producción, recepción y reproducción simbólica. Así, se nos propone trabajar el tejido textual como el lugar de producción semiótica, en donde texto y discurso representan perspectivas complementarias, que se colocan en un mismo nivel al momento de la producción de sentido.

Las orientaciones y de derroteros de la investigación semiótica de los últimos años en Puerto Rico plantean la noción de discurso como 
el lugar de manifestación de los procesos de significación, articulado éste a través de unas textualidades en donde convergen e interactúan diversidades y pluralidades de sujetos. Desde esta perspectiva, se entiende el discurso como una categoría social. Es el lugar de embate entre las formas de organización social y los sistemas de signos para la producción y reproducción de estos. Por lo tanto, produce, reproduce o transforma los conjuntos de significados o valores que organizan al grupo cultural, es decir, queda constituido a partir de la interacción entre un conjunto de enunciados y un conjunto de acciones. Esta orientación en la noción de discurso nos lleva a que las semióticas se abren hacia la discusión y problematización de procesos sociales inscritos en la multiplicidad de discursos que son articulados mediante la interacción comunicativa, llevada a cabo entre diversos sectores culturales, y la variedad de textualidades generadas a través de las diferentes tecnologías y procesos de la comunicación, e intercambios comunicativos.

La siguiente bibliografía mínima ejemplifica esta sucinta reflexión en torno al desarrollo de la semiótica en Puerto Rico.

\section{Bibliografia Mínima}

\section{A. Las estructuras textuales y el trazado de los recorridos narrativos}

FORASTIERI BRASCHI, EDUARDO (1976). Aproximación estructural al teatro de Lope de Vega. Madrid, San Juan: Hispanova de Ediciones.

- (1980). On text and context: methodological approaches to the contexts of literature. Río Piedras, P.R.: Editorial Universitaria, Universidad de Puerto Rico.

COlón ZaYAs, Eliseo R. (1985). El teatro de Luis Rafael Sánchez: códigos, ideología y lenguaje. Madrid: Editorial Playor.

DUCHESNE WINTER, JUAN (1990). Narraciones de testimonio en America Latina: cinco estudios. Río Piedras, P.R.: EDUPR.

- (1992). Las tribulaciones de Juliá. San Juan, P.R.: Instituto de Cultura Puertorriqueña.

- (1996). Política de la caricia: ensayos sobre corporalidad, erotismo, literatura y poder. San Juan P.R.: Libros Nómadas; Río Piedras, P.R.: Decanato de Estudios Graduados e Investigación de la Universidad de Puerto Rico. 
GelPf, JuAN (1993). Literatura y paternalismo en Puerto Rico. San Juan, P.R.: Editorial de la Universidad de Puerto Rico.

LÓPEZ BARALT, MERCEDES (1981). La crónica de Indias como texto cultural: policulturalidad y articulación de códigos semióticos múltiples en el arte de reinar de Guamán Poma de Ayala.

- (1992). La gestación de Fortunata y Jacinta: Galdós y la novela como re-escritura. Río Piedras, P.R.: Ediciones Huracán.

SoTOMAYOR, ÁUREA MARIA (1994). Hilo de Aracne: literatura puertorriqueña hoy. San Juan, P.R.: Editorial de la Universidad de Puerto Rico.

\section{B. Reflexión Filosófico-Semiótica}

FORASTIERI BRASCHI, EDUARDO (1992). Sobre el tiempo de los signos. Madrid: Editorial Orígenes.

GL, CARLOS (1994). El orden del tiempo: ensayos sobre el robo del presente en la utopía puertorriqueña. San Juan, P.R.: Editorial Postdata.

- (1987). Ensayos críticos: apuntes para una filosofia crítica puertorriqueña. San Juan, P.R.: Edit. El Múcaro.

Guevara, Carlos (1989). El edipo o la constitución de la subjetividad a través del lenguaje y la comunicación: desde Lacan a Vygosky. San Juan, P.R.: Editorial Librotex.

\section{Investigación semiótica de trazado sociocultural}

Álvarez Curbelo, Silvia (1993). Del nacionalismo al populismo: cultura y política en Puerto Rico. Río Piedras, P.R.: Ediciones Huracán.

- (1996). Historias vivas: historiografía puertorriqueña contemporánea. San Juan de P.R.: Asociación Puertorriqueña de Historiadores y Editorial Postdata.

- (1997). Ilusión de Francia: arquitectura y afrancesamiento en Puerto Rico. San Juan, P.R.: Archivo de Arquitectura y Construcción de la Universidad de Puerto Rico.

LóPEZ, MARÍA MilaGRos (1992). La imperfección líbil de cada día: reflexiones en torno al sujeto y la vida cotidiana. Río Piedras, P.R.: Centro de Investigaciones Sociales, Universidad de Puerto Rico.

- (1994). Más allá de la bella (in)diferencia: revisión posfeminista y otras escrituras posibles. Coeditado con Heidi Figueroa Sarriera y Madeline Román. San Juan: Publicaciones Puertorriqueñas.

TORRECILlA, ARTURo (1995). El espectro posmoderno: ecología, neoproletario, intelligentsia. San Juan, P.R.: Publicaciones Puertorriqueñas. 


\section{Textos/discursos y sus matrices culturales}

Colón Zayas, Eliseo R. (1996). Publicidad, modernidad, hegemonía. San Juan, P.R.: Editorial de la Universidad de Puerto Rico.

Figueroa SARRIERA, HeIdI J. (1991). Las metáforas de «persona» en textos sobre inteligencia artificial y robótica.

Gil, Carlos e Irma Rivera Nieves, editores (1995). Polifonía Salvaje: Ensayos de cultura y política en la postmodernidad. San Juan: Editorial Postdata. 